\title{
Euphemistic Strategies Used in Subtitling English Taboo Expressions into Chinese: A Case Study of Big Little Lies
}

\author{
Shuangjiao $\mathrm{Wu}^{1}$, Qian Wan ${ }^{2}$ \\ ${ }^{1}$ Department of Translation and Interpreting, Zhejiang Yuexiu University, Shaoxing, China \\ ${ }^{2}$ Department of English, College of English, Zhejiang Yuexiu University, Shaoxing, China \\ Email:sky_shuangjiao@163.com
}

How to cite this paper: Wu, S. J., \& Wan, Q. (2021). Euphemistic Strategies Used in Subtitling English Taboo Expressions into Chinese: A Case Study of Big Little Lies. Open Journal of Social Sciences, 9, 397-406. https://doi.org/10.4236/jss.2021.96027

Received: June 17, 2021

Accepted: June 26, 2021

Published: June 29, 2021

Copyright $\odot 2021$ by author(s) and Scientific Research Publishing Inc. This work is licensed under the Creative Commons Attribution International License (CC BY 4.0).

http://creativecommons.org/licenses/by/4.0/ (c) (i) Open Access

\begin{abstract}
This study aims to analyse the euphemistic strategies used in translating taboo words in a parallel corpus, an English-Chinese corpus of subtitles of the TV series Big Little Lies Season 1. A range of examples from the first season of the series are classified into three categories of taboo areas: sex-related terms, same sex-related terms and private body organs. The study analyzes the data quantitively and qualitatively. The findings of the study reject the assumption that euphemistic strategies would be more frequently used when translating the above taboo words into Chinese version. As to the translation of taboo words, the translation strategies used to render the three categories of taboo words are as follows: literal translation, widening and omission. In the whole corpus, the most frequently used translation strategy is literal translation, accounting for $88.6 \%$, while the euphemistic strategies, which include omission and widening, only account for $11.4 \%$ in total.
\end{abstract}

\section{Keywords}

Parallel Corpus, Big Little Lies, Taboo Words, Translation Strategies

\section{Introduction}

The evolvement of television industry is considered a main factor which has contributed to the globalization of the world into a small village. Almost every household nowadays has at least one television that communicates information and entertainment and gathers family members to watch their favorite shows. This growth has increased the demand on importing foreign shows to appeal to the viewers, which in turn increased the demand on translating these shows into 
the viewers' first language. Therefore, a new mode of translation, namely audiovisual translation (AVT), has been introduced into television to overcome the language barriers and facilitate the travel of information and entertainment across geographical borders.

Although AVT helped spread entertainment among different countries with different languages, cultural barriers proved stronger than the geographical ones; a barrier which has always been an obstacle when it comes to translation in all its different modes (Al-Jabri et al., 2021). This cultural barrier seems to aggravate the problem when the two languages/cultures involved are distant, such as English and Chinese. Therefore, the subtitler is expected to work out technical, linguistic, and cultural obstacles. One of these cultural problems is taboo words.

It is no secret that political authorities have a great influence on the content of these shows and what should and should not be aired. Probably this influence is due to the nature of Chinese society which does not accept the public discussion of certain taboo areas including sex and gay relationships, among others. Therefore, the author assumes that Chinese version of American TV series would show that euphemistic strategies would be more frequently used in the translation of taboo words.

To test this assumption, this study aims to investigate the translation strategies used in delivering taboo words found in the first season of the American TV series Big Little Lies produced by HBO. An analysis of the Chinese version of the American TV series will be conducted in three main categories of taboo words including sex-related terms, same sex-related terms and private body organs.

\section{Review of Related Literature}

As discussed earlier in the introduction, AVT has made a huge contribution to the TV industry. With the translation of foreign shows into different languages, information and entertainment crossed language barriers. According to Díaz-Cintas \& Ramael (2014), AVT covers two main modes; audio translation including dubbing or voice-over, and visual translation including subtitles using television, cinema, and other devices such as computers and mobile phones. Dubbing is an oral translation activity which depends on the use of the acoustic channel in screen translation while subtitling is the process of transferring a source language (SL) audiovisual media to a target language (TL) synchronized with the original verbal message (Díaz-Cintas \& Ramael, 2014).

The job of the subtitler is considered by many scholars as more complicated than that of the translator; it does not only require a high level of linguistic and cultural knowledge between the two languages, but also the possession of a wide range of other technical skills.

It's known that the nature of taboo words differs from one culture to another and many factors come into play when determining what can be said and what cannot be said in a certain culture. However, almost every society has a set of taboos which act as a broad umbrella under which different words or topics are 
considered prohibited in public. The translation of taboo words in subtitling is an under-researched area in audiovisual translation in general and in subtitling in particular. The existing studies normally focus on the connotative equivalence of English taboo words and their Arabic correspondence in audiovisual translation (AVT) (Al-Yasin \& Rabab'ah, 2019) and strategies chosen by the Ndebele translators in the translation of taboo terms (Ndhlovu \& Botha, 2017). However, in the case of the Chinese language, the use of euphemistic strategies used in the translation of English taboo words is an under-researched area. Therefore, the present study, in this sense, contributes to this academic field.

In this study, the classification of taboo areas is inspired by several previous studies which discussed taboo language (Gao, 2013: p. 2310; Al-Jabri et al., 2021; Al-Adwan, 2015). They mention that taboos are names of prohibited things and acts that are associated mainly with customs and political authority and which cannot be discussed in public. These taboo subjects include bodily functions about sex and excretion, the private parts, illnesses and death, words believed to be blasphemy, income, salary, age of ladies, etc. (Gao, 2013: p. 2310).

Euphemism, according to Al-Jabri et al. (2021), is defined as "a word or a phrase used in a specific linguistic and extra-linguistic context to soften or conceal something unpleasant". As discussed above, therefore, euphemism is a politeness strategy used by communicators to tone down the effect of inappropriate words or taboos in a particular culture or a particular context.

\section{Euphemism Strategies}

The current study will rely mainly on the euphemistic strategies suggested by Williams (1975) and Warren (1992) and further developed by Al-Adwan (2015) to conduct the analysis of the American TV series Big Little Lies. These strategies include:

1) Widening: This strategy involves substituting the offensive word with a more general term that is less offensive.

2) Implication: According to Al-Adwan (2015: p. 11), implication involves two propositions, where the second is usually a logical consequence of the first. Normally, the euphemisms generated through this process have a conventional meaning, and, at the same time, imply a novel interpretation.

3) Omission: As the term suggests, this strategy occurs when subtitlers/translators decide to remove a word that is deemed to be seriously offensive or face threatening.

\section{Data and Methodology}

\subsection{Research Objectives}

The general objective of the present study is to analyse the euphemistic strategies used in translating taboo words in the parallel corpus, an English-Chinese corpus of subtitles of the TV series Big Little Lies Season 1.

In order to attain this general objective, the following specific aims have been 
pursued:

- To retrieve and classify all the instances of taboo words in the English sub-corpus;

- To identify and classify all the euphemistic strategies adopted to translate the SL taboo words in the Chinese subtitles.

\subsection{Data Collection}

It was suggested by Hatim and Mason (1997) that the audiovisual work that suits research should 1) be a widely-distributed, full-length feature work with high quality subtitles; 2) be work where interpersonal pragmatics are brought to the fore; and 3) contain many sequences of verbal interaction such as sparring (Cheng, 2019).

The corpus being used in this research is the first season of Big Little Lies produced by $\mathrm{HBO}$, which contains seven episodes. Based on Liane Moriarty's best seller and featuring Reese Witherspoon, Nicole Kidman, Shailene Woodley and more. Big Little Lies is a dark comedy set in a town by the seaside in California. The characters in the show who deal with daily topics include marriage, professional career, socializing and so forth. This wide range of topics and situations yield diverse use of verbal exchanges including the use of taboos or culturally unacceptable terms making the show a rich research material. In addition, the TV series Big Little Lies made itself a great success due to the acting and scripts. It was rated highly on different film commentary websites, with ratings such as 9.0/10 (Douban Movies, 2017), 89\% (Rotten Tomatoes, 2017) and 8.5/10 (IMDb, 2017). Thus, the TV series Big Little Lies meets the above standard set by Hatim and Mason (1997), and fits the purpose of this research.

The Chinese translation chosen in this article is done by "YYeTs" (人人影视, Ren-Ren-Ying-Shi), being one of the largest fansub groups in China and known for its reputable quality in audiovisual translation. Fansub (a short form of "fan subtitled") is an emerging topic in Translation Studies. It was earlier defined by Diaz Cintas as "a fan-produced, translated, subtitled version of a Japanese anime programme", but now also refers to such versions of other audiovisual works (Cheng, 2019).

Because of its high quality, YYeTs's translation has been used by various legitimate video distributers online, including Souhu (搜狐, Sou-Hu), Youku (优 酷, You-Ku) and 163.com (网易, Wang-Yi) (Wang \& Zhang, 2015). Such recognition gives credence to the translation quality of Big Little Lies carried out by YYeTs. This research uses the proofread version of the translation to build the corpus.

To build the corpus, both English and Chinese subtitles from Big Little Lies from season one on the YYeTs website were collected. All seven episodes of season one are selected based on the translation quality. The English and Chinese subtitles are paralleled manually, because the number of the two versions of subtitles doesn't match. The reason is that there is copyright information about 
translation done by the fansub YYeTs. Thus, such information has been deleted in the process of paralleling. Then, a corpus is established consisting of three columns after paralleling: the serial number of the subtitle, the source text, and the target text.

\subsection{Research Stages}

The researcher used the following steps to collect and analyze the data:

- Retrieval of all the instances of taboo words that fall into the selected categories outlined in the introduction from the parallel corpus; Al-Adwan (2015) points out that the taboo area of sex includes a wide range of topics among which are romantic and sexual relationships, body parts (especially organs related to sex) and sexual orientation. The current study will deal only with these taboo areas.

- Classification of all the examples regarding the three categories mentioned earlier: sex-related terms (words/phrases referring to sexual relationships), same sex-related terms, and private body organs.

- Identification and clarification of the translation strategies adopted in each case.

- Analysis of the results and drawing of conclusions.

\section{Results and Discussion}

As mentioned earlier, the current case study focuses on the three categories of taboos. As Figure 1 reflects, the most frequent category found in the English subtitles is that of the sex-related terms, accounting for $81 \%$ of the total number of the ST taboo words analyzed, followed by the category of private body organs, which represents $17 \%$, and by the category of same sex-related terms, with $3 \%$. Each section in the following will discuss one of these categories with relevant examples detected in the corpus. The above three categories are sex-related terms, same sex-related terms and private body organs.

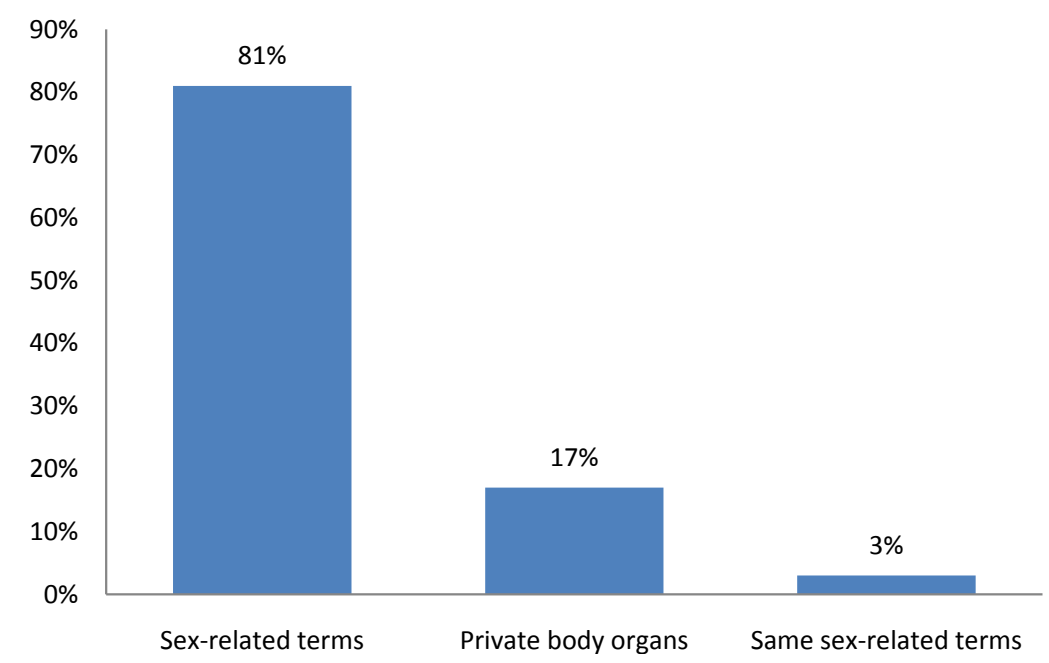

Figure 1. Frequency of taboo words in the whole corpus. 


\subsection{Sex-Related Terms}

Sex is a source of embarrassment and discomfort in many cultures, especially if discussed in public. However, the degree of threat caused by this subject differs from society to another. In the Chinese culture, sex is a subject that is threatening to the face of most Chinese people if discussed publicly.

In the first season of the discussed TV series, references to sex detected surpass the other two categories of taboo words. This section will discuss the sex-related terms found in the first season. The most commonly used references to the act of sexual activity detected in the corpus include have sex with, get laid, make love and sleep with. See Table 1. These English phrases, although differ in register, are direct references to the act of having sex that would trigger a sense of embarrassment for most Chinese viewers.

With an analysis of the translation strategies adopted by YYeTs in the translation of these phrases, it could be noticed that almost $92.6 \%$ of the sex-related terms in the English ST are replaced with the literal equivalent in the TT. While only $7.4 \%$ of these phrases are translated into the TT with the euphemism strategy widening. See Figure 2.

By using literal translation, as the term indicates, the author refers to the literal translation of the taboo words in the ST. Thus, in Example 1, the word sex is translated into 性爱 (xing-ai) in the TT. In addition, the phrase have sex in

Table 1. Season 1. References to sex-related terms.

\begin{tabular}{|c|c|}
\hline English ST & \multirow{2}{*}{$\begin{array}{l}\text { Chinese TT } \\
\text { 1. 你曾说过你们俩很少有性生活 }\end{array}$} \\
\hline 1. You once said that you two don't have [[sex]] very often. & \\
\hline 2. that Ziggy wasn't a product of consensual, loving $[[\operatorname{sex}]]$.. & 2. 得知齐格不是两情相悦的结晶 \\
\hline 3. Because $[[\operatorname{sex}]]$ isn't always that. & 3. 因为性爱不总是这样 \\
\hline 4. ... I promise. Get [[laid]], bitch. See you later. ... & 4. 这么焦躁就去找个男人啊 \\
\hline 5. I'd [[sleep]] with either. & 5. 我愿意跟其中任何一个上床 \\
\hline$\cdots$ & $\cdots$ \\
\hline $100.0 \%$ & \\
\hline \multicolumn{2}{|l|}{$90.0 \%$} \\
\hline \multicolumn{2}{|l|}{$80.0 \%$} \\
\hline \multicolumn{2}{|l|}{$70.0 \%$} \\
\hline \multicolumn{2}{|l|}{$60.0 \%$} \\
\hline \multicolumn{2}{|l|}{$50.0 \%$} \\
\hline \multicolumn{2}{|l|}{$40.0 \%$} \\
\hline \multicolumn{2}{|l|}{$30.0 \%$} \\
\hline \multicolumn{2}{|l|}{$20.0 \%$} \\
\hline \multicolumn{2}{|l|}{$10.0 \%$} \\
\hline \multicolumn{2}{|l|}{$0.0 \%$} \\
\hline Literal translation & Widening \\
\hline
\end{tabular}

Figure 2. Translation strategy used to render sex-related terms in the corpus. 
Example 2 is translated into 性生活 (xing-sheng-huo) in the Chinese subtitles, which is very close as that in the ST.

Example 1:

English subtitles: Because [[sex]] isn't always that.

Chinese subtitles: 因为性爱不总是这样

Back translation: Because sex isn't always that.

Example 2:

English subtitles: You once said that you two don't have [[sex]] very often.

Chinese subtitles: 你曾说过你们俩很少有性生活

Back translation: You once said that you two don't have sex very often.

The term widening is used here to refer to the translation of the taboo words with a more general term in the TL. An example of this strategy is the translation of loving sex into 两情相悦 (liang-qing-xiang-yue) in the TL. In this case, the use of 两情相悦 is more general in the Chinese subtitles.

Example 3:

English subtitles: ...that Ziggy wasn't a product of consensual, loving [[sex]]...

Chinese subtitles: 得知齐格不是两情相悦的结晶...

Back translation: ...Ziggy wasn't a product of two people falling in love with each other...

\subsection{Private Body Organs}

Private body organs, particularly those related with sex or bodily functions, are considered taboos by many cultures including the Chinese culture. Therefore, the use of these organs in public is expected to result in a sense of embarrassment or discomfort for most viewers in Chinese culture. Table 2 outlines the examples of taboo terms of this category along with their Chinese subtitles.

Figure 3 indicates that the translation strategies identified in the translation of this category of taboo words are omission, accounting for $66.7 \%$, and literal translation, with $33.3 \%$.

As the term omission suggests, this strategy occurs when translators decide to

Table 2. Season 1. References to private body organs.

\begin{tabular}{|c|c|}
\hline 1. that won't make my [[ass]] look fat? & 1. 屁股增肥的巧克力制的东西吗 \\
\hline 2. I'm gonna kick your fucking [[ass]] & 2. 我就踢爆你的屁股 \\
\hline 3. Personally, I'd rather shove an electric eel up my [[ass]] & 3. 就我而言 我宁愿被电鳗爆菊 \\
\hline 4. Stick that up your tight [[ass]], bitch! & 4. 这下被呛得没话说了吧 贱人 \\
\hline 5. I might have grabbed his [[ass]]. & 5. 我可能还掐了他屁股 我不记得了 \\
\hline $\begin{array}{l}\text { 6. You're gonna get your [[ass]] kicked tonight, you know } \\
\text { that? }\end{array}$ & 6. 你今晚会完败 知道吗 \\
\hline
\end{tabular}




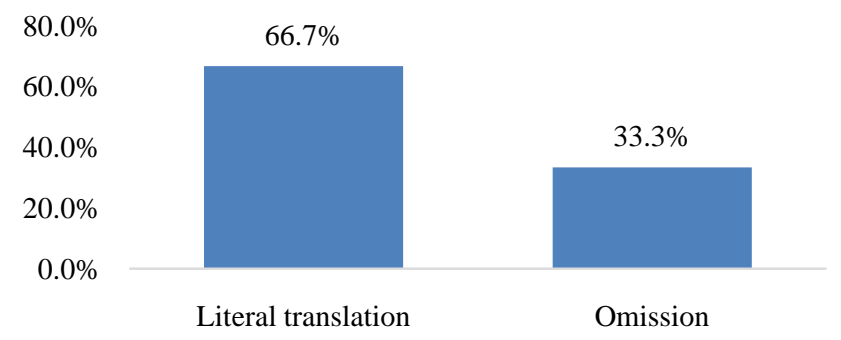

Figure 3. Translation strategy used to render private body organs in the corpus.

remove a word in the translation. The following Example 4 could be used to explain the translation strategy. In the TT, no taboo words are used to render the meaning of ass in the ST.

Example 4:

English Subtitles: You're gonna get your [[ass]] kicked tonight, you know that? Chinese subtitles: 你今晚会完败 知道吗

Back translation: You're gonna end up with a complete defeat tonight, you know that?

\subsection{Same Sex-Related Terms}

Although same sex relationships exist in the Chinese society, they are viewed as a psychological disorder rather than a personal choice. Table 3 demonstrates examples of same sex-related terms found in the corpus along with their Chinese versions. The two examples listed below are both rendered with the strategy of literal translation. The words gay and same-sex marriage are both replaced with 同性恋 (tong-xing-lian) and 同性婚姻 (tong-xing-hun-yin) respectively in the Chinese subtitles.

Table 3. Season 1. References to same sex-related terms.
1. Unfortunately, [[gay]].
1. 真可惜 他是同性恋
2. ... with love, and racism, and [[same-sex]] marriage, which are all re ...
2. 种族歧视和同性婚姻

\section{Conclusion}

This study investigated the translation strategies used by YYeTs in delivering taboo words found in the first season of the American TV series Big Little Lies. The author assumed that the Chinese version produced by YYeTs would show that euphemistic strategies would be more frequently used in the renderings of the taboo words. A range of examples from the first season of the series were classified into three categories of taboo areas: sex-related terms, same sex-related terms and private body organs. These topics are considered taboos in the Chinese culture, and could evoke a sense of embarrassment or threaten the face of Chinese viewers. The analysis started from the euphemistic strategies proposed by Al-Adwan (2015) to explain the strategies applied by subtitlers to render the face-threatening terms identified in the corpus. 


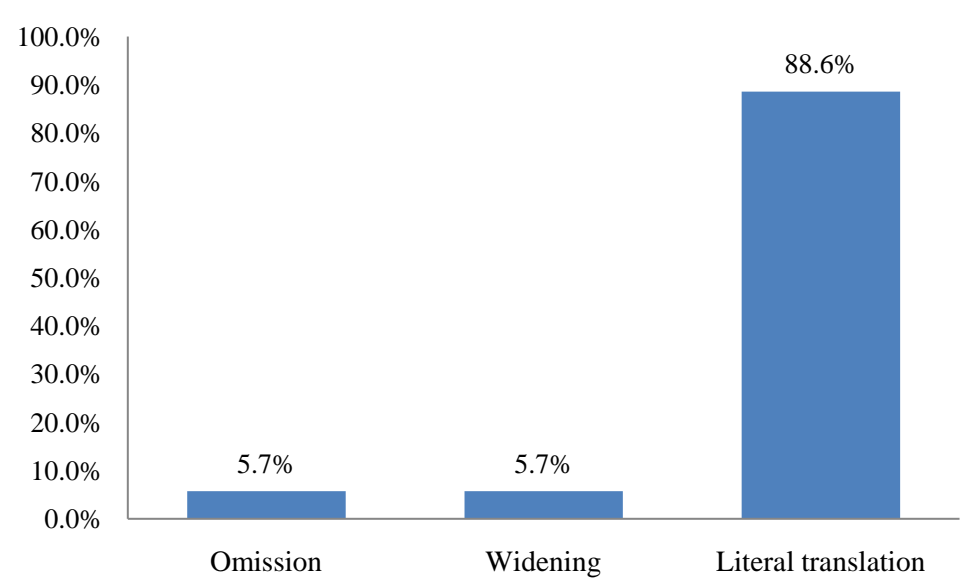

Figure 4. Translation strategies used to render the taboo words in the whole corpus (\%).

The findings of the study reject the assumption that Chinese version of the series provided by YYeTs would show that euphemistic strategies would be more frequently used. As to the translation of taboo words, the translation strategies used to render the three categories of taboo words are as follows: literal translation, widening and omission. In the whole corpus, the most frequently used translation strategy, as shown in Figure 4, is literal translation, accounting for $88.6 \%$, while the euphemistic strategies, which include omission and widening, only account for $11.4 \%$ in total.

It could be observed that the subtitlers didn't opt for a more general term to replace the taboo terms or omit the taboo terms. Instead, they used literal equivalents in most examples to render the taboo terms found in the corpus.

The reasons accounting for the above findings could be that the Chinese viewers, especially the middle-aged viewers and the viewers at their twenties who are the main target audience of the TV series, are not conservative as before, which lead to the change of their attitude toward the use of taboo words. In addition, the fansub groups may not under the same restrictions as that the satellite TV channel would undergo in China.

There are a few limitations in the present paper, such as, the size of the sample which consists of only the first season of an American TV series. In addition, the scope of this paper is limited to the investigation of euphemistic strategies of English taboo words and their Chinese correspondences in the fan subtitling.

Future research could tackle the issue of translating taboo words further by studying a larger sample of subtitles. Another issue could be studied in further research when the translation is in the opposite direction. Researchers may study how Chinese movies are translated in the English subtitles, and if there are taboo words in the Chinese movies, how they would be translated to English.

\section{Conflicts of Interest}

The author declares no conflicts of interest regarding the publication of this paper. 


\section{References}

Al-Adwan, A. (2015). Towards a Model of Euphemisation in Arabic Subtitling. Arab. Arab World English Journal, 4, 6-21.

Al-Jabri, H., Allawzi, A., \& Abushmaes, A. (2021). A Comparison of Euphemistic Strategies Applied by MBC4 and Netflix to Two Arabic Subtitled Versions of the US Sitcom How I Met Your Mother. Heliyon, 7, e06262. https://doi.org/10.1016/j.heliyon.2021.e06262

Al-Yasin, N. F., \& Rabab'ah, G. A. (2019). Arabic Audiovisual Translation of Taboo Words in American Hip Hop Movies. Babel, 65, 222-248. https://doi.org/10.1075/babel.00090.aly

Cheng, Z. (2019). Omission of Subject "I” in Subtitling: A Corpus Review of Audiovisual Works. Translation Horizons, No. 2, 43-77, 143.

Díaz-Cintas, J., \& Ramael, A. (2014). Audiovisual Translation, Subtitling. London: Routledge. https://doi.org/10.4324/9781315759678

Douban Movie (2017). Big Little Lies Season 1. https://movie.douban.com/subject/25953429/

Gao, C. (2013). A Sociolinguistic Study of English Taboo Language. Theory and Practice of Language Studies, 3, 2310-2314. https://doi.org/10.4304/tpls.3.12.2310-2314

Hatim, B., \& Mason, I. (1997). The Translator as Communicator. London: Routledge.

IMDb (2017). Big Little Lies. https://www.imdb.com/title/tt3920596/

Ndhlovu, K., \& Botha, R. (2017). Euphemism vs Explicitness: A Corpus-Based Analysis of Translated Taboo Words from English to Zimbabwean Ndebele. South African Journal of African Languages, 37, 235-243. https://doi.org/10.1080/02572117.2017.1378278

Rotten Tomatoes (2017). Big Little Lies. https://www.rottentomatoes.com/tv/big little lies

Wang, D., \& Zhang, X. (2017). Fansubbing in China: Technology-Facilitated Activism in Translation. Target: International Journal of Translation Studies, 29, 301-318. https://doi.org/10.1075/target.29.2.06wan

Warren, B. (1992) What Euphemisms Tell Us about the Interpretation of Words. Studia Linguistica, 46, 128-172. https://doi.org/10.1111/j.1467-9582.1992.tb00833.X

Williams, J. (1975). Origins of the English Language. New York, NY: Free Press. 